\title{
Prevalence estimates and risk factors for early childhood wheeze across Europe: the EuroPrevall birth cohort
}

\author{
Anna Selby, ${ }_{1}^{1}$ Alasdair Munro, ${ }^{2}$ Kate E Grimshaw, ${ }_{1}^{1,3}$ Victoria Cornelius, ${ }^{4}$ Thomas Keil, $^{5,6}$ \\ Linus Grabenhenrich, ${ }^{7,8}$ Michael Clausen, ${ }^{9}$ Ruta Dubakiene, ${ }^{10}$ Alessandro Fiocchi, ${ }^{11}$ \\ Marek L Kowalski, ${ }^{12}$ Nikolaos G Papadopoulos, ${ }^{13,14}$ Marta Reche, ${ }^{15}$ \\ Sigurveig T Sigurdardottir, ${ }^{16}$ Aline B Sprikkelman, ${ }^{17}$ Paraskevi Xepapadaki, ${ }^{13}$ \\ E N Clare Mills, ${ }^{18}$ Kirsten Beyer, $^{19}$ Graham Roberts ${ }^{1,20,21}$
}

- Additional material is published online only. To view please visit the journal online (http://dx.doi.org/10.1136/ thoraxjnl-2016-209429).

For numbered affiliations see end of article.

Correspondence to Professor Graham Roberts, Paediatric Allergy and Respiratory Medicine, Southampton University Hospital NHS Foundation Trust Southampton S016 6YD, UK; g.c.roberts@soton.ac.uk

Received 13 September 2016 Revised 8 January 2018 Accepted 29 January 2018 Published Online First 10 May 2018

\section{Linked}

- http://dx.doi.org/10.1136/ thoraxjnl-2018-211660

Check for updates

To cite: Selby A, Munro A, Grimshaw KE, et al. Thorax 2018;73:1049-1061.

\section{ABSTRACT}

Background Preschool wheeze is an important problem worldwide. No comparative population-based studies covering different countries have previously been undertaken.

Objective To assess the prevalence of early childhood wheeze across Europe and evaluate risk factors focusing on food allergy, breast feeding and smoke exposure. Methods Infants from nine countries were recruited into the EuroPrevall birth cohort. At 12 and 24 months, data on wheeze, allergic signs/symptoms, feeding, smoke exposure, infections and day care attendance were collected using questionnaires. Poisson regression was used to assess risk factors for wheeze.

Results 12049 infants were recruited. Data from the second year of life were available in 8805 (73.1\%). The prevalence of wheeze in the second year of life ranged from $<2 \%$ in Lodz (Poland) and Vilnius (Lithuania) to $13.1 \%(95 \% \mathrm{Cl} 10.7 \%$ to $15.5 \%)$ in Southampton (UK) and $17.2 \%$ (95\% Cl 15.0\% 19.5\%) in Reykjavik (Iceland). In multivariable analysis, frequent lower respiratory tract infections in the first and second years of life (incidence rate ratio (IRR) $1.9(95 \% \mathrm{Cl} 1.3$ to 2.6 ) and 2.5 (95\% Cl 1.9 to3.4), respectively), postnatal maternal smoking (IRR 1.6, 95\% Cl 1.1 to 2.4 ), day care attendance (IRR 1.6, 95\% Cl 1.1 to 2.5 ) and male gender (IRR $1.3,95 \% \mathrm{Cl} 1.0$ to 1.7 ) were associated with wheeze. The strength of their association with wheeze differed between countries. Food allergy and breast feeding were not independently associated with wheeze. Conclusion The prevalence of early childhood wheeze varied considerably across Europe. Lower respiratory tract infections, day care attendance, postnatal smoke exposure and male gender are important risk factors. Further research is needed to identify additional modifiable risk factors that may differ between countries.

\section{INTRODUCTION}

Preschool wheeze affects approximately one-third of children in the first 3 years of life placing a substantial burden on healthcare resources. ${ }^{12}$ Genetic factors play a role in the aetiology of preschool wheeze and asthma. ${ }^{3}$ However, the International Study of Asthma and Allergies in Childhood (ISAAC) and European Community Health

\section{Key messages}

What is the key question?

- How does the prevalence of early childhood wheeze vary across Europe and what are the key risk factors?

What is the bottom line?

- This study demonstrated that the prevalence of early childhood wheeze varies considerably across Europe and that lower respiratory tract infections, postnatal maternal smoking, day care attendance and male gender are important risk factors.

Why read on?

- This is the first multicentre cohort study to compare the prevalence of and explore risk factors for early childhood wheeze across Europe.

Respiratory Survey (ECHRS) recognised that environmental factors are predominantly responsible for geographical variations in the prevalence of asthma. These studies examined international prevalence patterns of asthma symptoms in school-age children and adults, respectively. ${ }^{45}$ One study has investigated preschool wheeze at age 4 years, but this used data from 10 independent cohorts in eight countries. ${ }^{6}$ Further examining variations in prevalence rates of preschool wheeze within a single multicentre cohort may provide new aetiological clues.

Established risk factors for preschool wheeze include male gender, a family history of allergic disease, cigarette smoke exposure, respiratory tract infections and day care attendance. ${ }^{2} 378$ The role of breast feeding in the development of allergic disease and asthma has been extensively investigated with inconclusive findings. ${ }^{9-11}$ Several studies have reported that exclusive breast feeding for at least 4 months protects against childhood wheezing. ${ }^{12} 13$ However, others have suggested that delaying the introduction of solids may increase the risk. ${ }^{14}$ Methodological differences may account 
for discrepancies between studies. Therefore, large multicentre studies would help to clarify the role of infant feeding practices in the development of preschool wheeze. Another knowledge gap that needs to be addressed is the relationship between food allergy and preschool wheeze. Numerous studies have shown that food allergy and asthma are closely linked. ${ }^{16}$ However, few studies have investigated the relationship between food allergy and preschool wheeze. In particular, studies using double-blind placebo-controlled food challenges (DBPCFC) are lacking.

This study aimed to determine the prevalence of wheeze in the first 2 years of life across Europe. It further aimed to evaluate risk factors for wheeze, focusing on food allergy, infant feeding and cigarette smoke exposure. We hypothesised that early-onset food allergy increases the risk of early childhood wheeze and that longer duration of breast feeding and increased overlap between breast feeding and solids are protective. Many other potential influences were considered, including exposure to cigarette smoke during pregnancy and infancy, birth weight, birth length and gestation.

\section{METHODS}

\section{Study design}

The EuroPrevall birth cohort was established between 2005 and 2010. The methodology and baseline characteristics have previously been reported. ${ }^{1718}$

Evaluation began at birth with follow-up of participants at 12 and 24 months using standardised questionnaires based on those used in previous epidemiological studies such as ISAAC. Questionnaires were administered via phone or in person by trained personnel. Additional assessments, including skin prick testing, measurement of specific IgE with or without a DBPCFC were performed according to a standardised protocol whenever parents reported symptoms suggestive of food allergy in their children. ${ }^{17} 18$

\section{Study population}

Families were recruited antenatally and postnatally from nine study centres: Reykjavik (Iceland), Southampton (UK), Amsterdam (The Netherlands), Berlin (Germany), Lodz (Poland), Vilnius (Lithuania), Madrid (Spain), Milan (Italy) and Athens (Greece). ${ }^{17}$

Inclusion criteria were a gestational age of at least 34 weeks and a good condition at birth (Apgar score of at least 7 at 5 minutes). Families unable to give informed consent and infants participating in other studies examining allergic disease were excluded. Written informed consent was obtained from all parents. ${ }^{17} 18$

Follow-up questionnaires were not always completed at the intended ages of 12 months and 24 months. Participants were included in this analysis if data were collected between the ages of 6 months and less than 18 months (1-year data) or 18 months and 30 months of age (2-year data).

\section{Exposures}

At recruitment, data were collected on birth details, maternal diet, family history, maternal education (as a marker of socioeconomic status) and environmental exposures, including cigarette smoke and pet ownership.

The 12-month and 24-month questionnaires included an extensive list of foods found in children's diets. Parents were asked if their child had tried each food and if so, when they first tried it. Parents were also asked if their child had ever been breast fed and, if so, for how long. Using these data, the age of each child when solids were first introduced and the overlap (in months) between breast feeding and solids was determined.

A number of dichotomous smoking variables were generated using data collected at baseline and 12 months. These are described in appendix $A$, along with other baseline and follow-up variables, which were assessed as potential risk factors. These included day care attendance, respiratory tract infections and eczema.

Food allergy was defined as a positive DBPCFC or clear history of anaphylaxis to any food in the first 24 months of life. Children with food allergy were subdivided into those with IgE-mediated and non-IgE-mediated food allergy. IgE-mediated food allergy was defined as food allergy with a positive skin prick test ( $\geq 3 \mathrm{~mm}$ weal) or positive specific $\operatorname{IgE}(\geq 0.35 \mathrm{kU} / \mathrm{L})$ at any time during follow-up.

\section{Outcomes}

Wheeze in the second year of life was the primary outcome for this analysis. Questions relating to wheeze included: 'In the last 12 months, has your child had wheezing or whistling in the chest?' (12-month questionnaire) and 'Between the ages of 13-24 months, has your child had wheezing or whistling in the chest when they did not have a cold?' (24-month questionnaire). Children were defined as having wheeze in the second year of life if parents answered yes to either of these questions within the specified time range for 2-year data. A secondary analysis comparing those with recurrent wheeze (wheeze in both the first and second years of life) to a never wheezed group was undertaken.

\section{Statistical analysis}

Statistical analysis was undertaken using STATA SE V.13. The baseline characteristics and exposures of participants were described for the whole cohort, separately for each centre and those with and without wheeze in the second year of life. No data were imputed. Differences between centres were examined, appropriate descriptive statistics were undertaken and differences were compared using $\chi^{2}$ (dichotomous/categorical variables), one-way analysis of variance (continuous, normally distributed variables) or Kruskal-Wallis (continuous, non-normally distributed variables).

Poisson regression was used to identify risk factors for wheeze in the second year of life. Variables associated with wheeze ( $\mathrm{P}$ value $<0.1$ ), food allergy and variables related to feeding and cigarette smoke exposure were entered into a multivariable model. A dummy variable for study centre (using Reykjavik as the baseline centre) was included in the model to account for heterogeneity between centres. Variables were not included if they were explained by combinations of others, for example, allergic disease and allergic rhinitis. Three alternative multivariable models were generated in a sensitivity analysis. Sensitivity model one was derived by applying backward deletion to the primary model; that is, variables were sequentially removed (starting with the variable with the weakest association with wheeze) until only those with a P value $\leq 0.05$ remained in the model. Sensitivity models two and three were similar to the primary model and sensitivity model one, respectively, but did not include study centre. Likelihood ratio tests were used to test the goodness of fit of the multivariable models. Significant associations from the primary model were entered into a separate multivariable model to examine their importance in individual centres. 


\section{RESULTS}

\section{Participants}

The EuroPrevall cohort included 12049 infants. A total of 6189 (51.4\%) were male. The baseline characteristics of participants varied considerably between centres (table 1 and online supplementary table S1) ${ }^{18}$ After excluding participants followed up outside the specified age ranges for 1-year and 2-year data, follow-up data were available in 8174 infants (67.8\%) at 1 year and in 8805 infants $(73.1 \%)$ at 2 years (figure 1). Follow-up rates varied between centres (online supplementary table S2). The baseline characteristics of those with 2 -year data were similar to those without (online supplementary table S3).

\section{Prevalence of wheeze and potential risk factors}

The prevalence of wheeze in the second year of life across all centres was $7.8 \%$, ranging from $1.7 \%$ in Lodz to $17.2 \%$ in Reykjavik (table 2 and figure 2). Large differences in the prevalence of recurrent wheeze were also seen, ranging from $0.3 \%$ in Vilnius to $10 \%$ in Reykjavik (table 2).

Among children included in this analysis, the prevalence of food allergy ranged from $0.1 \%$ in Athens to $3 \%$ in Southampton. The majority of cases of food allergy were IgE mediated (table 3). The mean duration of breast feeding was 6.1 months overall, ranging from 4.3 months in Athens to 8.5 months in Reykjavik. The age at introduction of solids was similar across Europe ranging from 5.0 months to 5.7 months. Maternal smoking habits (during pregnancy and postnatally) also varied considerably between centres (table 3 ).

\section{Association of risk factors with wheeze in the second year of life}

Food allergy

$21.5 \%$ of infants with food allergy had wheeze in the second year of life compared with $7.6 \%$ of infants without. Although food allergy was associated with wheeze in the second year of life in univariate analysis (raw incidence rate ratio (IRR) 2.84, $95 \%$ CI 1.92 to $4.20, \mathrm{P}<0.001$ ) (table $4 \mathrm{a}$ ), this association was not consistent across centres (online supplementary table S6) and was not significant after adjusting for potential confounders (adjusted IRR 1.26, 95\% CI 0.55 to 2.91, P 0.589) (table 4a).

\section{Feeding practices}

In univariate analysis, breast feeding, longer duration of breast feeding and increased overlap of breast feeding/solids were associated with a lower prevalence of wheeze in some centres (online supplementary table S6). In the primary model, however, none of these factors were statistically significant (table 4a). Increased overlap of breast feeding/solids showed a small protective effect against wheeze (adjusted IRR 0.95, 95\% CI 0.90 to 1.00 ) in sensitivity model one (table 4a).

\section{Smoke exposure}

Univariate analysis suggested that any maternal smoking increases the risk of wheeze in the second year of life (raw IRR $1.29,95 \%$ CI 1.11 to 1.50, P 0.001), while having other household smokers decreases the risk of wheeze (raw IRR 0.81, $95 \%$ CI 0.66 to $0.98, \mathrm{P} 0.033$ ). However, neither of these factors were independently associated with wheeze in the second year of life (table 4a). Maternal smoking at 1-year follow-up was a statistically significant risk factor for wheeze in multivariable analysis (adjusted IRR 1.62, 95\% CI 1.09 to 2.42, P 0.017) (table 4a).
Other potential risk factors

Other factors associated with wheeze in the second year of life in univariate analysis included male gender, higher birth weight, eczema, a family history of allergic disease, day care attendance and frequent ( $\geq$ quarterly) respiratory tract infections. Dog ownership and longer birth length were associated with a lower prevalence of wheeze (table $4 \mathrm{~b}$ ). In multivariable analysis, only frequent lower respiratory tract infections (LRTIs) in the second year of life (adjusted IRR 2.50, 95\% CI 1.83 to $3.41, \mathrm{P}<0.001)$, frequent LRTIs in the first year of life (adjusted IRR $1.87,95 \%$ CI 1.33 to $2.64, \mathrm{P}<0.001$ ), day care attendance (adjusted IRR 1.63, 95\% CI 1.08 to 2.45, P 0.020), maternal smoking at 1-year follow-up (adjusted IRR 1.62, 95\% CI 1.09 to $2.42, \mathrm{P} 0.017$ ) and male gender (adjusted IRR 1.33, 95\% CI 1.03 to $1.70, \mathrm{P} 0.027$ ) were statistically significant risk factors for wheeze (tables $4 \mathrm{a}$ and $4 \mathrm{~b}$ ). Male gender and frequent LRTIs were also risk factors for recurrent wheeze, along with maternal allergy and paternal asthma (online supplementary table S5).

\section{Alternative models}

When 'study centre' was removed from the primary model, paternal allergy (adjusted IRR 1.36, 95\% CI 1.01 to $1.83, \mathrm{P}$ 0.004), frequent upper respiratory tract infections (URTIs) in the first year of life (adjusted IRR $1.55,95 \%$ CI 1.09 to 2.19 , P 0.014 ) and frequent URTIs in the second year of life (adjusted IRR 1.62 , 95\% CI 1.11 to 2.36 , P 0.012 ) were identified as risk factors for wheeze (online supplementary table S4).

The association between the risk factors identified by the primary model and wheeze in the second year of life varied between centres (table 5). In Southampton, for example, only male gender (IRR 1.66, 95\% CI 1.00 to $2.76, \mathrm{P} 0.050$ ) and maternal smoking at 1-year follow-up (adjusted IRR 2.72, 95\% CI 1.29 to 5.7 , P 0.009) were statistically significant risk factors for wheeze.

\section{DISCUSSION}

This study has demonstrated that the prevalence of parent-reported wheeze in the first 2 years of life varies considerably across Europe with a broadly northwestern to southeastern gradient. The strongest risk factors for wheeze were lower respiratory tract infections, day care attendance, postnatal maternal smoking and male gender. Many other potential risk/protective factors including food allergy and breast feeding were evaluated. None of these had a significant influence on the prevalence of wheeze in the second year of life.

\section{Wheeze prevalence}

The prevalence of wheeze in the second year of life across all centres was $7.8 \%$. For the Netherlands, the estimated prevalence of wheeze (11\%) was lower than in the Generation R study. This estimated the prevalence of wheeze in Rotterdam at 2 years to be $20 \% .^{19}$ Our estimates for Southampton (13\%), Berlin (12\%) and Amsterdam (11\%) were, however, similar to the $12 \%$ estimate in the Pollution and Asthma Risk: an Infant Study (PARIS) birth cohort. ${ }^{8}$ Our study is the first multicentre cohort study to assess the prevalence of early childhood wheeze across Europe. The prevalence of wheeze in the second year of life was nearly 10-times higher in Reykjavik and Southampton than in Lodz and Vilnius. In keeping with our findings, the ISAAC study and ECRHS reported a high prevalence of wheeze in Western Europe with lower prevalences in Eastern and Southern Europe. ${ }^{20}$ Countries represented in EuroPrevall, ISAAC and ECRHS included the UK, Germany, Italy, Spain and 


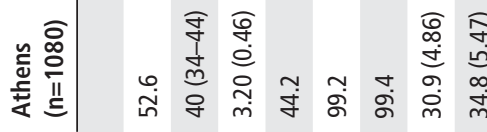

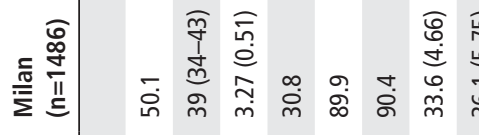

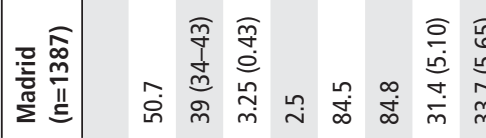

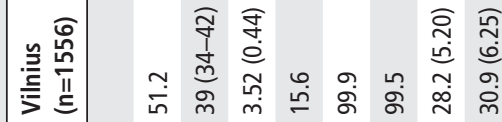

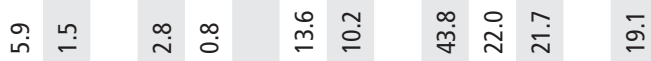

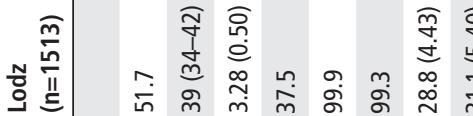

तิ

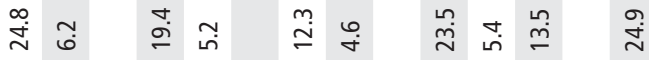

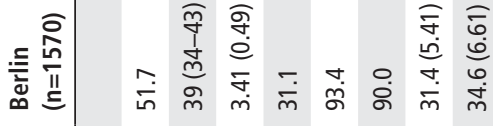

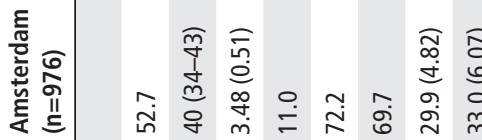

5

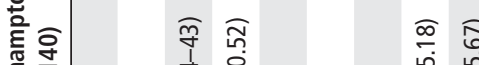

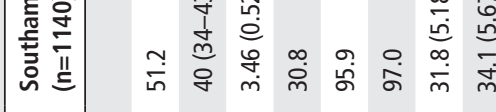

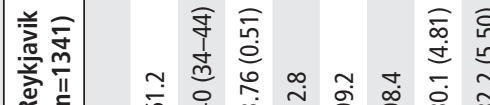

न

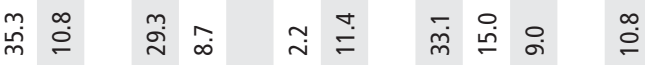

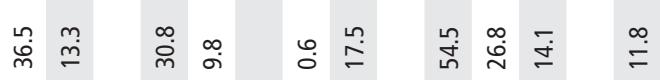

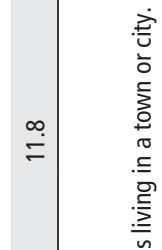

近

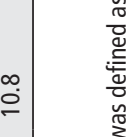

๕ั in

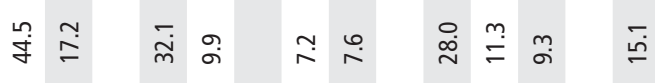

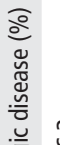
$\frac{2}{\frac{2}{2}}$ 


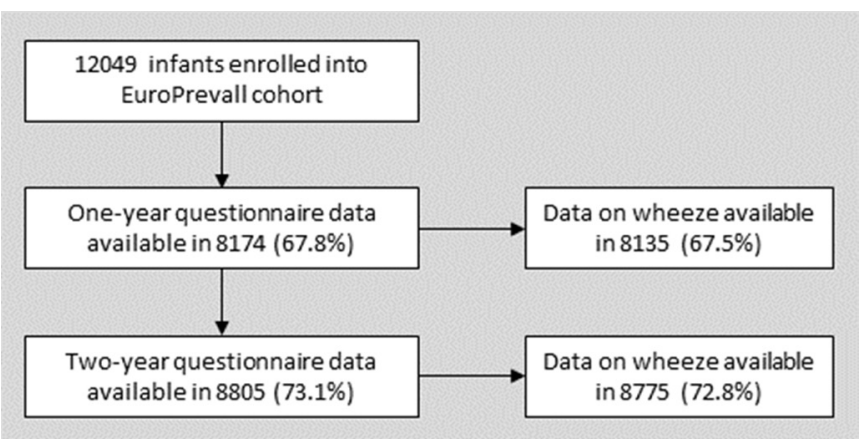

Figure 1 EuroPrevall participants included in this analysis.

Greece. Across these countries, the prevalence of self-reported wheeze/diagnosed current asthma (ECHRS) was highest in the UK and lowest in Greece in all three studies. ${ }^{21} 22$ This suggests that common factors are driving early childhood wheeze and asthma in later life.

\section{Risk factors for early childhood wheeze}

The allergic march describes the progression from eczema in early childhood to asthma and allergic rhinitis later on. ${ }^{23} 24$ The role of food allergy in this is unclear ${ }^{24}$ though food allergy is known to be associated with asthma at school age. ${ }^{25}$ A substantial number of children who wheeze in infancy later develop asthma. $^{2} 26$ Therefore, we hypothesised that food allergy is a risk factor for wheeze in the first 2 years of life. Although food allergy was significant in univariate analysis, when potential confounders were considered, no association with wheeze was seen. According to the primary model, this was also true for eczema. In keeping with our results, the Urban Environment and Childhood Asthma study reported no association between food allergy (diagnosed according to $\operatorname{IgE}$ levels $\geq 0.35$ and a history suggestive of food allergy) and wheeze in the first 2 years life, ${ }^{27}$ and in the Tuscon Children's Respiratory Study, eczema was not a risk factor for transient early wheezing. ${ }^{2}$ A likely explanation for these findings is that early childhood wheeze is predominantly driven by respiratory tract infections rather than atopy. Indeed, LRTIs were associated with wheeze in all of the multivariable models that we tested.

Day care attendance increases exposure to respiratory tract infections. ${ }^{28}$ Therefore, as expected, this was associated with wheeze in the second year of life. The PARIS and Prevention and Incidence of Asthma and Mite Allergy (PIAMA) birth cohorts also found that early day care attendance is associated with increased wheeze before the age of 4 years. ${ }^{8} 28$ Several studies have, however, reported a protective effect of day care attendance on asthma at school age, ${ }^{29-31}$ reflecting the fact that preschool wheeze and asthma are different entities. In a post hoc analysis, we investigated whether the relationship between day care and wheeze is influenced by age at entry to day care or the number of hours spent in day care in the first year of life. In univariate analysis, entering day care later was associated with a lower risk of wheeze (IRR 0.98 (per month increase), P 0.26, $95 \%$ CI 0.97 to 1.00$)$. However, neither age at entry to day care nor the number of hours spent in day care in the first year of life was significantly associated with wheeze in the second year of life when included in the primary model.

Of the smoking variables evaluated, only maternal smoking at 1-year follow-up was independently associated with wheeze in the second year of life. Previous studies have demonstrated that maternal smoking during pregnancy is an independent risk

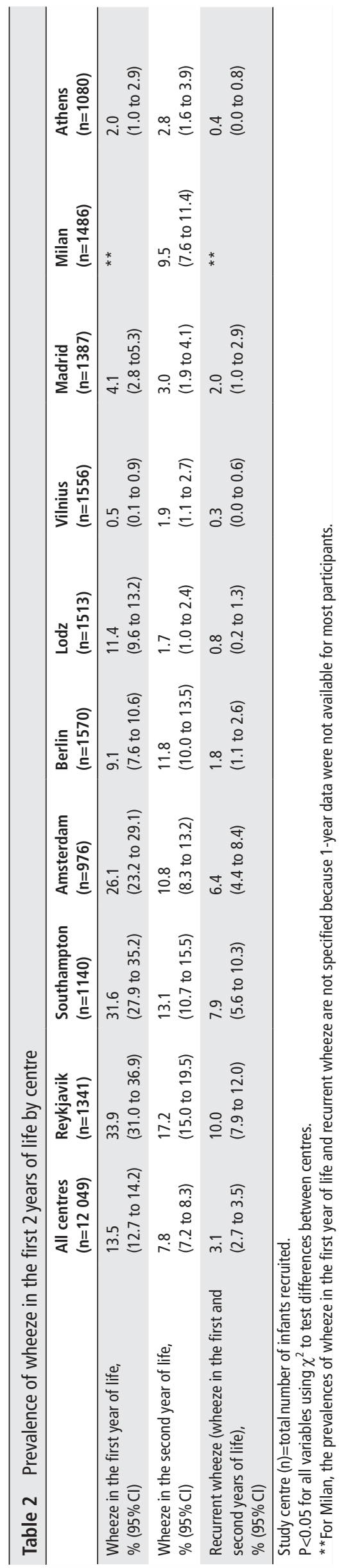




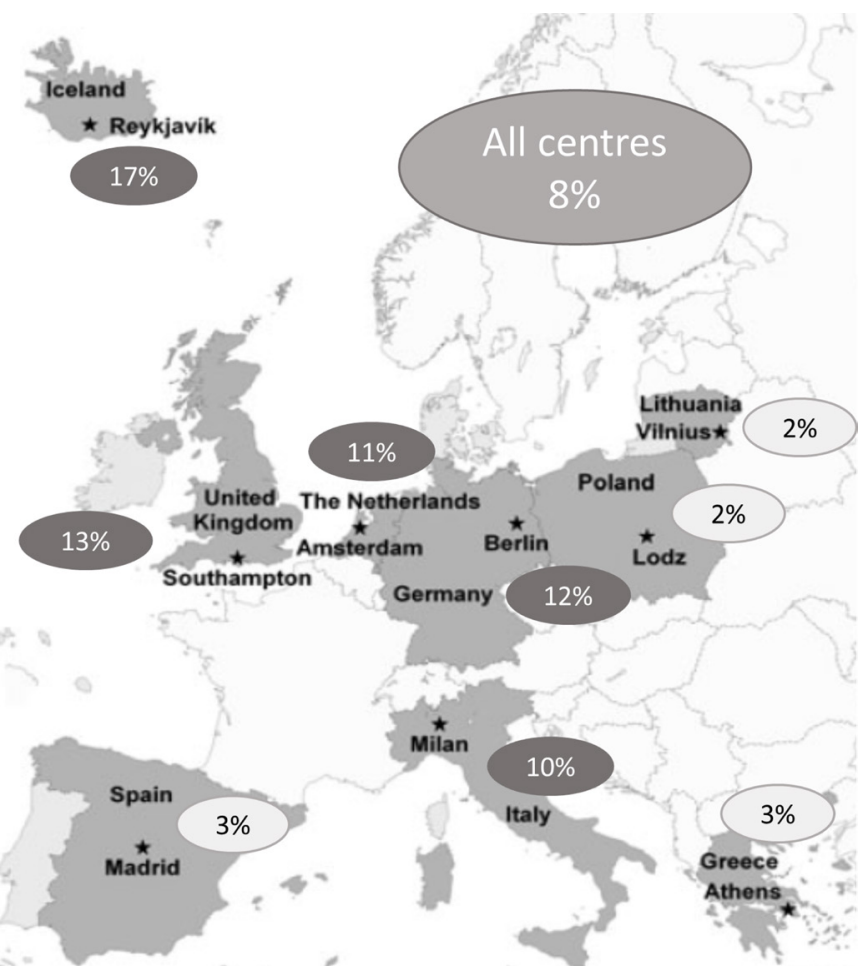

Figure 2 Map showing study centres and the prevalence of wheeze in the second year of life in each centre (adapted from Keil et al). ${ }^{17}$

factor for wheeze in infancy. ${ }^{19}{ }^{32-35}$ In this analysis, the number of cigarettes smoked during pregnancy and the timing of smoke exposure was not considered. This may account for the discrepancy between our findings and those of other studies. Another unexpected finding was that other household smokers were associated with a lower risk of wheeze in univariate analysis. However, once potential confounders were considered, there was a non-significant trend for other household smokers to increase the risk of wheeze.

Given breast milk contains antiviral antibodies, a protective effect on early childhood wheeze is plausible. ${ }^{11}$ It has previously been concluded that exclusive breast feeding for at least 4 months reduces the risk of recurrent wheeze in childhood. ${ }^{10}{ }^{11}$ However, we found no association between breast feeding or breast feeding duration and wheeze in the second year of life. This may be due to the fact that the mean duration of breast feeding was more than 4 months in all centres, making it more difficult to demonstrate a protective effect. Nevertheless, when the relationship between breast feeding duration and wheeze was analysed using a categorical variable based on quartiles, the same effect was seen. Increased overlap between breast feeding and solids showed a small protective effect against wheeze in sensitivity model one. Grimshaw et al previously demonstrated that concurrent feeding with breast and cow's milk reduces the risk of food allergy in infancy, ${ }^{36}$ while Snijders et al reported that delaying the introduction of cow's milk and solids increases the risk of eczema and wheeze, respectively. ${ }^{15}$ A potential explanation for these findings is that breast milk only has beneficial immunomodulatory effects when the immune system is exposed to other dietary proteins. ${ }^{36}$ Further research is needed to establish whether maximising the duration of overlap between breast and complementary feeding could help to prevent childhood wheeze.

Given that heterogeneity between centres in terms of both baseline factors and potential risk factors for wheeze was observed, the primary model and sensitivity model one were adjusted for study centre. Study centre was significant suggesting that unmeasured factors are operating in individual centres. Furthermore, when significant associations from the primary model were investigated by centre, their importance varied. Confounding between centres and these variables may partially explain differences between the unadjusted and adjusted model estimates. Climatic differences may also be important. For example, the colder climate in northern Europe may predispose to more frequent respiratory tract infections and hence wheeze.

\section{Strengths and limitations}

A potential limitation of any longitudinal study is loss to follow-up. As outlined in online supplementary table S1, follow-up varied between centres. The number of infants from Milan with 1-year data was especially low because the dates on which most participants' 12-month questionnaires were completed were not available. This made it impossible to determine the age of these infants at the time of data collection. Overall, however, ' 2 year' data were available in over $70 \%$ of participants, and the baseline characteristics of those with and without ' 2 year' data were similar.

At four centres, anonymous data on family history and education were collected from 2320 parents who declined participation. Parents who agreed to participate in the study had a higher level of education and were more likely to have a history of allergic diseases. ${ }^{18} 37$ Given that paternal allergic disease and maternal asthma were associated with wheeze in some models, the prevalence of wheeze among infants in the EuroPrevall cohort may be higher than in the general population.

Another important consideration is that wheeze prevalence estimates were dependent on parents' understanding of the term wheeze. ${ }^{38}$ Similarly, some children with viral rashes may have been wrongly classified as having eczema. This is suggested by the fact that the prevalence of eczema in individual centres was largely concordant with the prevalence of URTIs. To minimise the potential for misunderstanding, study questionnaires were translated from English into different languages and verified with back translation. Furthermore, they were based on the widely used ISAAC questionnaires, which have been validated in many languages for assessing wheeze and asthma in school-age children. ${ }^{49}$ Recall bias is possible given that some questionnaires were completed 6 months after the period for which they were intended to capture data.

Major strengths of this study are its size (allowing us to adjust for multiple confounders) and the fact that diagnoses of food allergy were confirmed by double-blind, placebo-controlled challenges.

\section{CONCLUSION}

This birth cohort study provides unique data on the prevalence of and risk factors for early childhood wheeze across Europe. Early onset food allergy and infant feeding practices were not associated with wheeze in second year of life. In keeping with previous studies, lower respiratory tract infections, day care attendance, maternal smoking in infancy and male gender were identified as important risk factors. The relationship between these and wheeze differed between centres, suggesting that additional risk factors may be operating in individual countries. Further research is needed to identify these. Meanwhile, preventing respiratory tract infections and minimising postnatal 


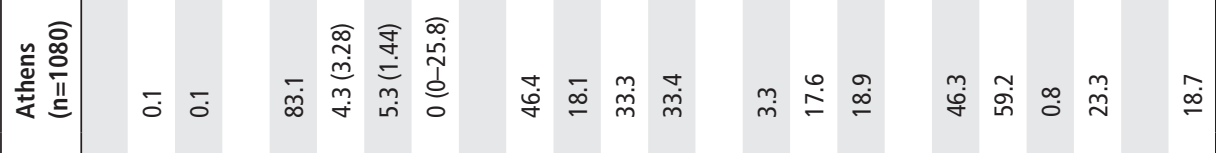

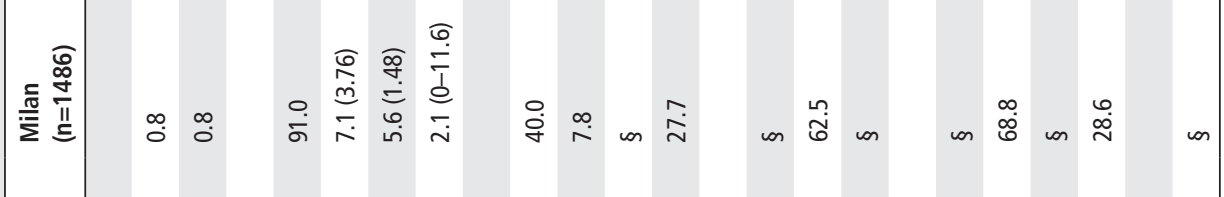

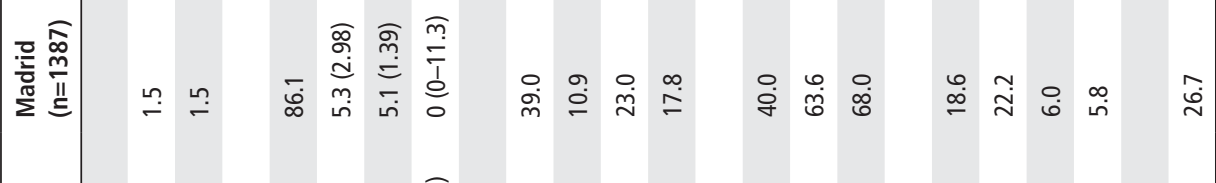

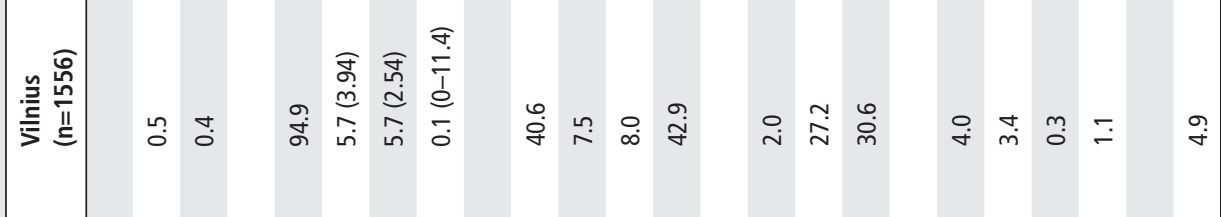

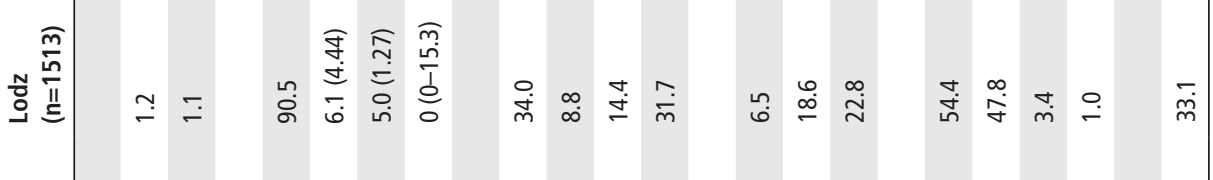

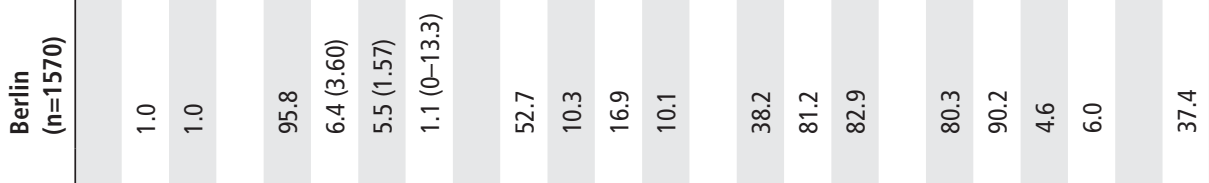

急

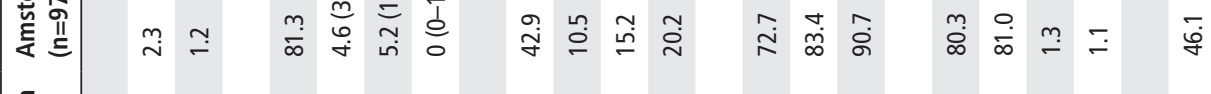

.

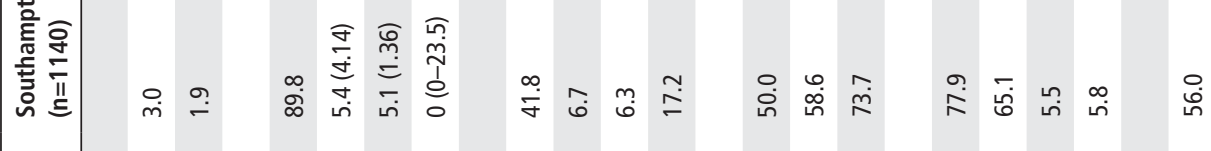

英

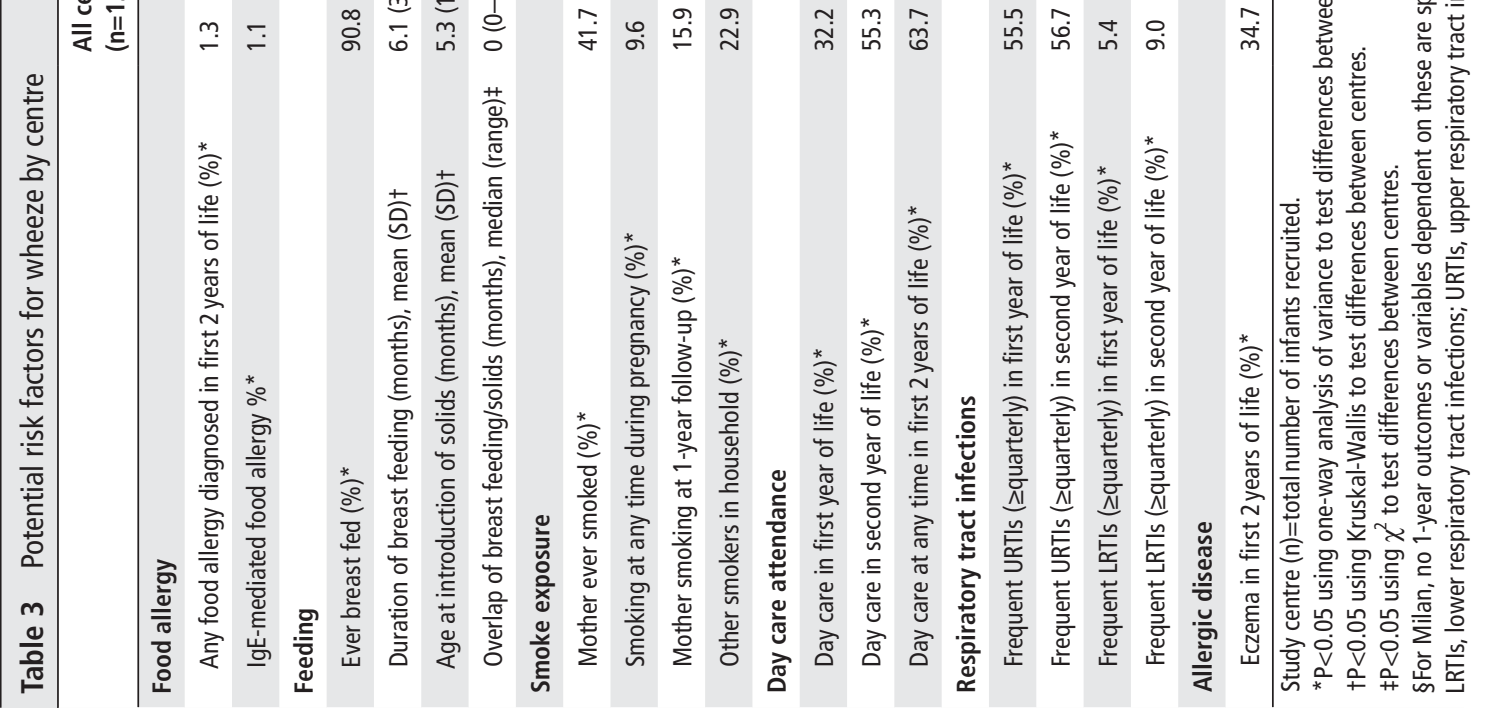




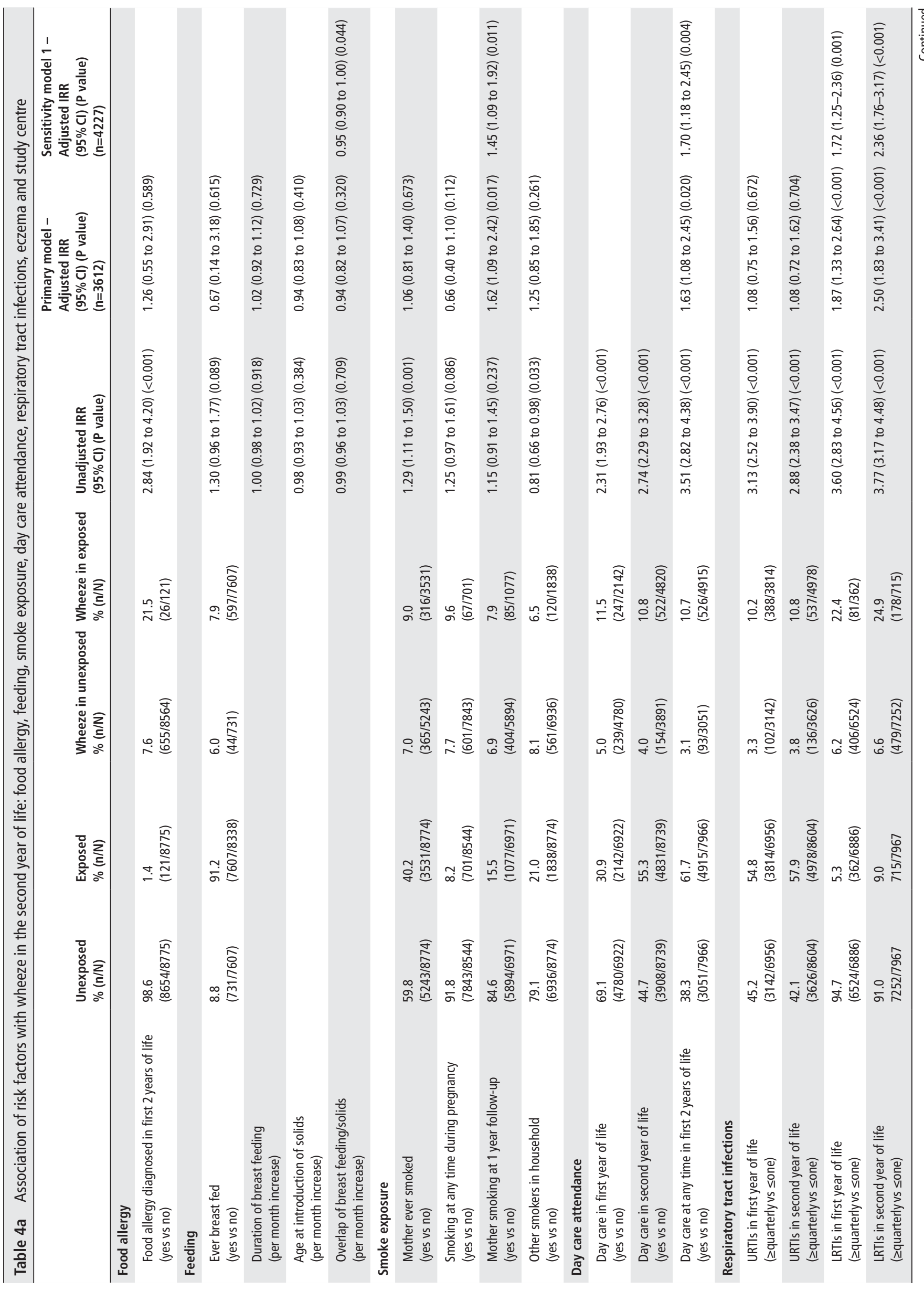




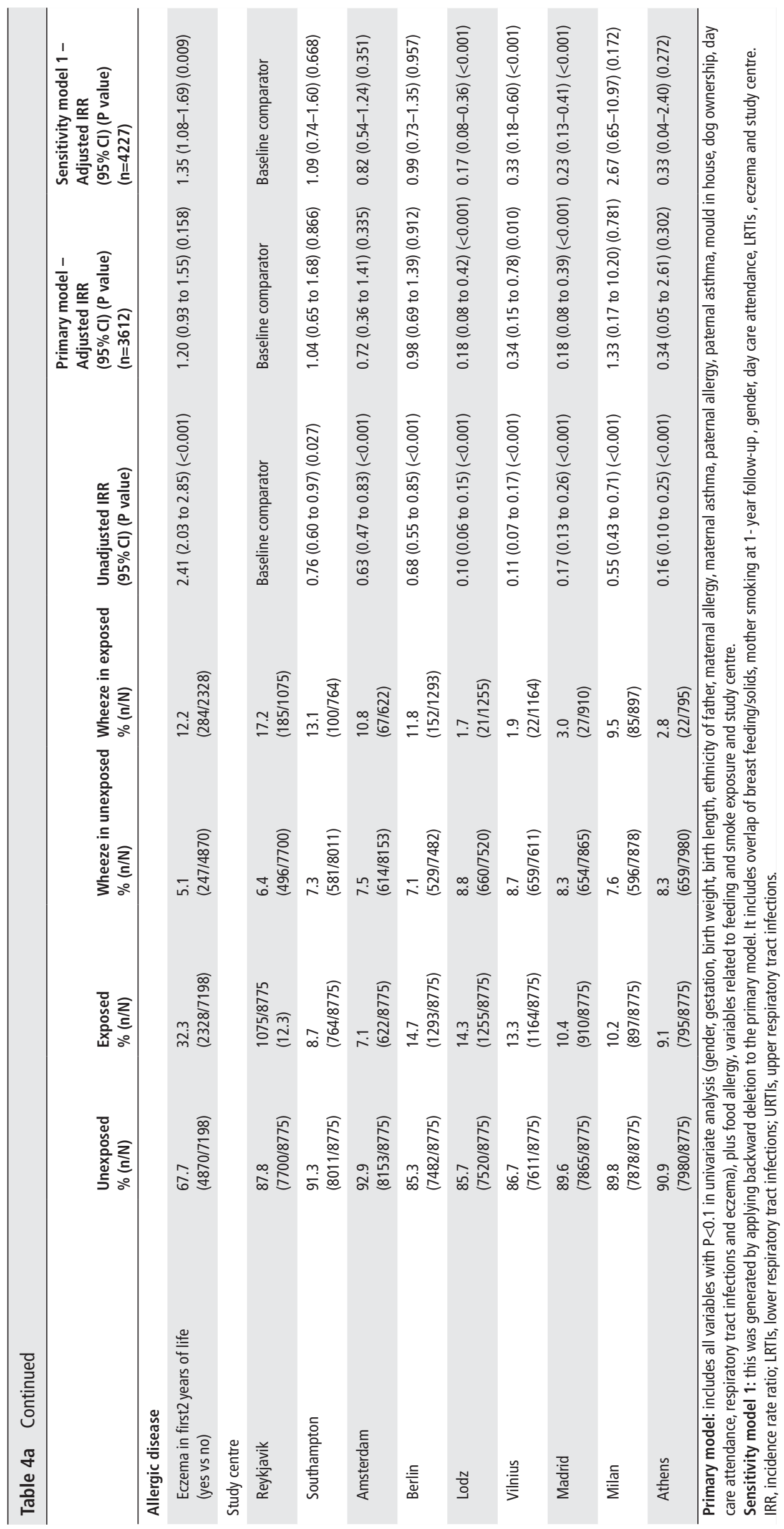




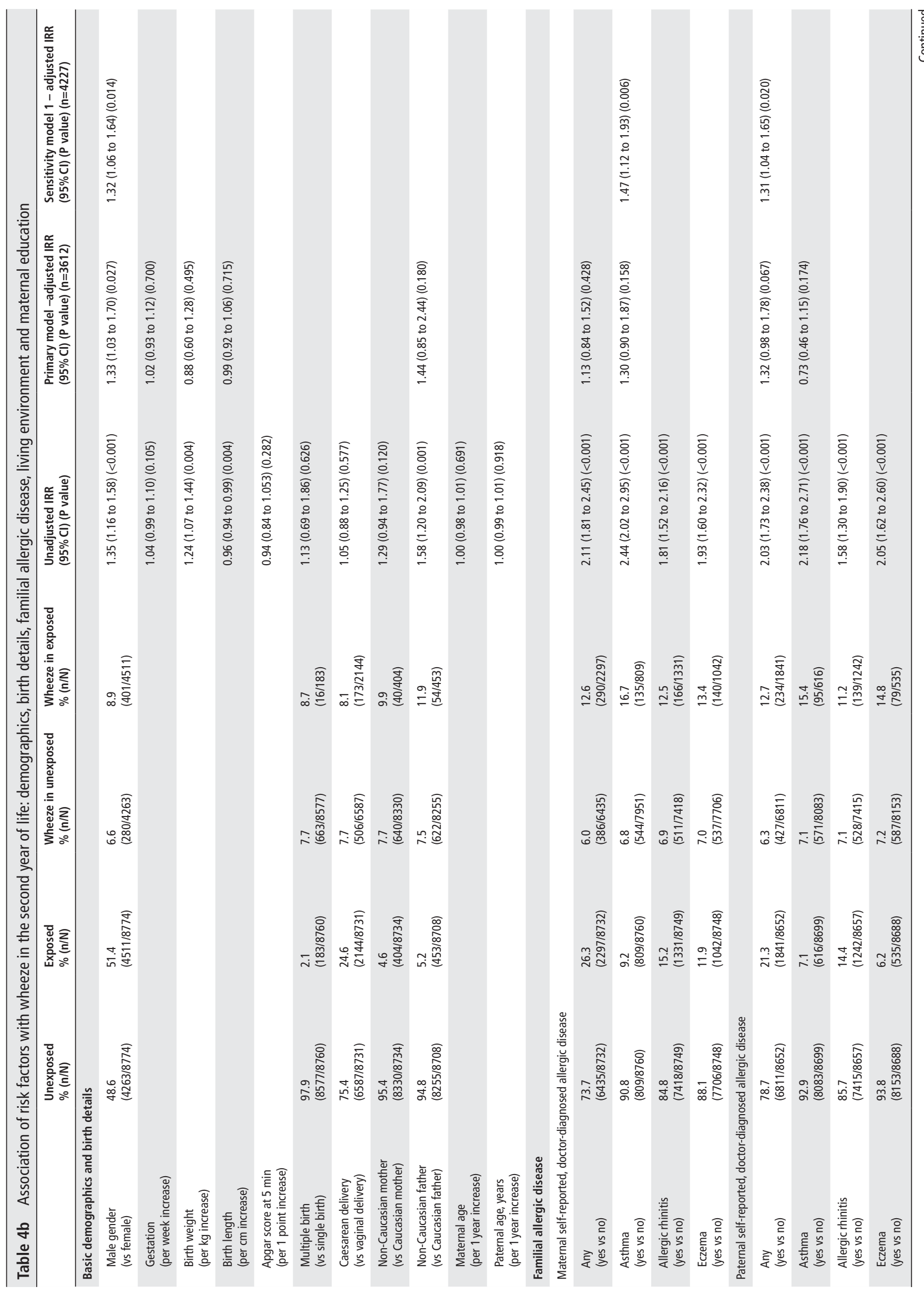

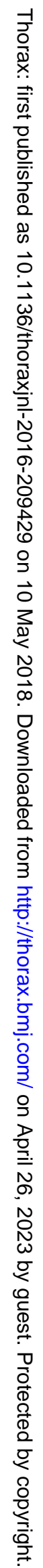




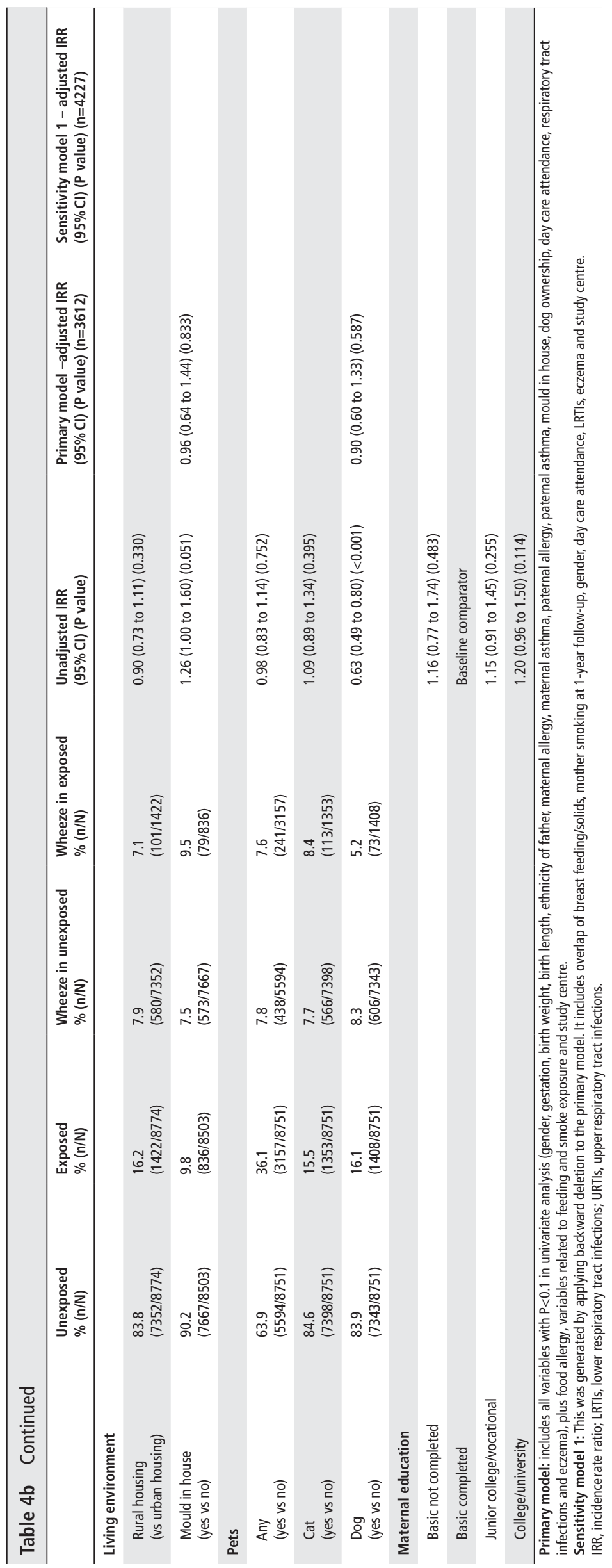


Table 5 Association of significant risk factors from primary model with wheeze in the second year of life by centre

\begin{tabular}{|c|c|c|c|c|c|c|c|c|c|}
\hline & Reykjavik & Southampton & Amsterdam & Berlin & Lodz & Vilnius & Madrid & Milan & Athens \\
\hline $\mathrm{n}$ & 829 & 494 & 569 & 1228 & 1084 & 1009 & 826 & & \\
\hline Male gender (vs female) & $\begin{array}{l}1.45 \\
\text { (1.02 to } 2.08) \\
(0.040)\end{array}$ & $\begin{array}{l}1.66 \\
(1.00 \text { to } 2.76) \\
(0.050)\end{array}$ & $\begin{array}{l}3.17 \\
(1.67 \text { to } 6.01) \\
(<0.001)\end{array}$ & $\begin{array}{l}1.72 \\
(0.84 \text { to } 1.63) \\
(0.346)\end{array}$ & $\begin{array}{l}1.28 \\
(0.45 \text { to } 3.65) \\
(0.643)\end{array}$ & $\begin{array}{l}2.00 \\
(0.74 \text { to } 5.32) \\
(0.167)\end{array}$ & $\begin{array}{l}1.02 \\
(0.46 \text { to } 2.25) \\
(0.966)\end{array}$ & - & - \\
\hline $\begin{array}{l}\text { Mother smoking at } 1 \text {-year } \\
\text { follow-up (yes vs no) }\end{array}$ & $\begin{array}{l}1.08 \\
(0.64 \text { to } 1.83) \\
(0.776)\end{array}$ & $\begin{array}{l}2.72 \\
(1.29 \text { to } 5.77) \\
(0.009)\end{array}$ & $\begin{array}{l}1.46 \\
(0.75 \text { to } 2.86) \\
(0.267)\end{array}$ & $\begin{array}{l}1.27 \\
(0.84 \text { to } 1.94) \\
(0.258)\end{array}$ & $\begin{array}{l}2.38 \\
(0.75 \text { to } 7.55) \\
(0.141)\end{array}$ & $\begin{array}{l}0.79 \\
(0.11 \text { to } 5.99) \\
(0.823)\end{array}$ & $\begin{array}{l}1.66 \\
(0.68 \text { to } 4.05) \\
(0.261)\end{array}$ & - & - \\
\hline $\begin{array}{l}\text { Day care at any time in first } \\
2 \text { years of life } \\
\text { (yes vs no) }\end{array}$ & $\begin{array}{l}1.30 \\
(0.41 \text { to } 4.09) \\
(0.656)\end{array}$ & $\begin{array}{l}1.16 \\
(0.69 \text { to } 1.95) \\
(0.570)\end{array}$ & $\begin{array}{l}1.71 \\
(0.67 \text { to } 4.34) \\
(0.258)\end{array}$ & $\begin{array}{l}1.67 \\
(1.01 \text { to } 2.77) \\
(0.047)\end{array}$ & $\begin{array}{l}1.91 \\
(0.65 \text { to } 5.61) \\
(0.237)\end{array}$ & $\begin{array}{l}3.66 \\
(1.47 \text { to } 9.13) \\
(0.005)\end{array}$ & $\begin{array}{l}0.69 \\
(0.31 \text { to } 1.53) \\
(0.365)\end{array}$ & - & - \\
\hline $\begin{array}{l}\text { LRTIs in first year of life } \\
\text { ( } \geq \text { quarterly vs } \leq \text { one) }\end{array}$ & $\begin{array}{l}1.83 \\
(1.28 \text { to } 2.65) \\
(0.001)\end{array}$ & $\begin{array}{l}1.85 \\
(0.82 \text { to } 4.17) \\
(0.138)\end{array}$ & $\begin{array}{l}2.33 \\
(0.56 \text { to } 9.63) \\
(0.243)\end{array}$ & $\begin{array}{l}1.30 \\
(0.63 \text { to } 2.66) \\
(0.478)\end{array}$ & $\begin{array}{l}2.48 \\
(0.32 \text { to } 19.18) \\
(0.384)\end{array}$ & $\begin{array}{l}24.9 \\
(2.98 \text { to } 207.18) \\
(0.003)\end{array}$ & $\begin{array}{l}2.42 \\
(0.86 \text { to } 6.80) \\
(0.093)\end{array}$ & - & - \\
\hline $\begin{array}{l}\text { LRTIs in second year of life } \\
\text { ( } \geq \text { quarterly vs } \leq \text { one) }\end{array}$ & $\begin{array}{l}2.74 \\
(1.92 \text { to } 3.92) \\
(<0.001)\end{array}$ & $\begin{array}{l}1.07 \\
(0.41 \text { to } 2.75) \\
(0.896)\end{array}$ & $\begin{array}{l}2.67 \\
(0.65 \text { to } 11.15) \\
(0.174)\end{array}$ & $\begin{array}{l}1.29 \\
(0.69 \text { to } 2.39) \\
(0.421)\end{array}$ & $\begin{array}{l}10.23 \\
(1.34 \text { to } 78.33) \\
(0.025)\end{array}$ & - & $\begin{array}{l}11.83 \\
(4.27 \text { to } 32.78) \\
(<0.001)\end{array}$ & - & - \\
\hline
\end{tabular}

Values represent: adjusted incidence rate ratio $(95 \% \mathrm{Cls})(\mathrm{P} \text { value })^{*}$.

Where no figures are entered, Poisson estimation was not possible.

*Only significant associations from the primary model (gender, mother smoking at 1-year follow-up, day care attendance and LRTls in the first and second years of life) were entered into the multivariable models for individual centres.

LRTIs, lower respiratory tract infections.

smoke exposure may help to reduce the burden of early childhood wheeze.

\section{Author affiliations}

${ }^{1}$ Clinical and Experimental Sciences and Human Development and Health Academic Units, Faculty of Medicine, University of Southampton, Southampton, UK ${ }^{2}$ Department of Paediatrics, Royal Hampshire County Hospital, Winchester, UK ${ }^{3}$ Department of Nutrition and Dietetics, Southampton Children's Hospital, Southampton, UK

${ }^{4}$ Imperial Clinical Trials Unit, School of Public Health, Imperial College London, London, UK

${ }^{5}$ Institute of Social Medicine, Epidemiology and Health Economics, Charité University Medical Centre, Berlin, Germany

${ }^{6}$ Institute for Clinical Epidemiology and Biometry, Julius-Maximilians-Universitat Wurzburg, Wurzburg, Germany

${ }^{7}$ Department for Infectious Disease Epidemiology, Robert Koch Institute, Berlin, Germany

${ }^{8}$ Department for Dermatology, Venerology and Allergology, Charité University Medical Centre, Berlin, Germany

${ }^{9}$ Children's Hospital, Landspitali - The National University Hospital of Iceland, Reykjavik, Iceland

${ }^{10}$ Faculty of Medicine, Vilnius University, Vilnius, Lithuania

${ }^{11}$ Division of Allergy, Ospedale Pediatrico Bambino Gesu, Roma, Italy

${ }^{12}$ Department of Immunology, Rheumatology and Allergy, Medical University of Lodz, Lodz, Poland

${ }^{13}$ Allergy Unit, 2nd Paediatric Clinic, University of Athens, Athens, Greece

${ }^{14}$ Centre for Paediatrics and Child Health, Institute of Human Development,

University of Manchester, Manchester, UK

${ }^{15}$ Hospital Universitario Infanta Sofía, San Sebastián de los Reyes, Madrid, Spain

${ }^{16}$ Department of Immunology, Landspitali - The National University Hospital of Iceland, Reykjavik, Iceland

${ }^{17}$ Department of Pediatric Pulmonology and Allergology, Beatrix Children's Hospital, University Medical Center Groningen, Groningen, The Netherlands

${ }^{18}$ Institute of Inflammation and Repair, Manchester Academic Health Science Centre, Manchester Institute of Biotechnology, University of Manchester, Manchester, UK

${ }^{19}$ Department of Paediatric Pulmonology and Immunology, Charité University Medical Centre, Berlin, Germany

${ }^{20} \mathrm{NIHR}$ Southampton Respiratory Biomedical Research Centre, University Hospital Southampton NHS Foundation Trust, Southampton, UK

${ }^{21}$ The David Hide Asthma and Allergy Research Centre, St Mary's Hospital, Isle of Wight, UK

Acknowledgements We would like to thank all of the families who participated in the EuroPrevall birth cohort study and the medical and nursing staff of the participating hospitals, particularly: Iceland: H Ragnarsdottir, AG Gunnarsdottir, H Sigurdardottir, G L Gudjonsdottir (Landspitali - The National University Hospital Reykjavik) and the prenatal care nurses at The Primary Health Care of the Reykjavik
Capital Area; UK: K Foote, E Oliver, L Gudgoen, T Kemp, R King, J Garland, E Francis, R Morris, S Pestridge, K Scally, E Gatrell, L Bellis, A Acqua, R Kemp, T Bryant and the NIHR Wellcome Trust Clinical Research Facility (Southampton); The Netherlands: Midwives, Zorggroep Almere (Department of Gynaecology and Obstetrics, Flevo Hospital Almere) N van den Berg (De Kinderkliniek Almere), W M C van Aalderen, L Hulshof and N C M Petrus (Emma Children's Hospital Academic Medical Center, Amsterdam); Germany: S Travis, S Paschke-Goossens, S Siegert, S Dufour, A Kafert, K Dobberstein, G Schulz, A Rohrbach, A Scholz, A Reich, M Kulig (Berlin) and M Wist (Munich); Poland: K Zeman (Medical University of Lodz), J Wilczynski and L Podciechowski (Polish Mother's Memorial Hospital, Lodz); Lithuania: I Butiene, D Vaicekauskaite, A Arlauskiene, J Zakareviciene and L Stoskute-Malinauskiene. Spain: M Martin-Esteban, S Quirce, R Gabriel, I I Larco, I Bobolea and T Cuevas (Madrid); Italy: A Martelli, P Realini, F Brandi (Allergia, the Italian Research Foundation for Allergy and Asthma Research), G R Bouygue, O Mazzina, M Busacca, T Sarratud and G Pezzoli (Milan); Greece: P Saxoni-Papageorgiou, K Zannikos, E Emmanouil, A Vasilopoulou, C Michopoulou, C Skordali (P y A Kyriakou Hospital), S Gavrili, G D Vlachos (Alexandra Hospital), A Malamitsi-Puchner, D Hasiakos, L Kontara (Areteion Hospital) and N Paparisteidis (Elena Venizelou Maternity Hospital, Athens).

Contributors ENCM was coordinator of the EuroPrevall project; KB was principal investigator of the birth cohort study. ACS, GR, KEG and AM performed the statistical analyses; TK, LG and VC provided statistical and epidemiological advice. ACS and GR drafted the manuscript. All authors reviewed and approved the final manuscript.

Funding The EuroPrevall birth cohort study was conducted within the collaborative research initiative EuroPrevall, an integrated project funded by the European Commission under the 6th Framework Programme (FOOD-CT-2005-514000), and Integrated Approaches to Food Allergy and Allergy Risk Management, a 7th Framework Collaborative Project (FP7-KBBE-2012-6). The UK birth cohort and the analysis for this paper was funded by the UK Food Standards Agency (T07046 and FS305019).

Competing interests GR received grants from the EU FP6 Programme and UK Food Standards Agency during the conduct of the study; KEG has received educational grants from Nutrica and speaker fees from Nutrica and Abbott; TK has received grants from the EU FP7 Programme outside of the submitted work; STS received grants from Landspitali University Hospital Science Fund, GlaxoSmithKline and the Icelandic Student Innovation Fund during the conduct of the study and has received non-financial support from Novartis and Thermo Fisher outside of the submitted work; ENCM has received grants from the UK Biological and Biotechnological Sciences Research Council, DBV Technologies, Reacta Biotech Ltd, the Medical Research Council, Innovate and the North West Lung Centre Charity outside of the submitted work and is founding director of Reacta Biotech Ltd; KB has received funding for research activities from the European Union, German Research Foundation, Berliner Sparkasse, BEA-Stiftung, Food Allergy and Anaphylaxis Network, Food Allergy Initiative, Danone, Thermo Fisher and DST Diagnostics. Other authors have no competing interests to declare.

Ethics approval Ethics approval was obtained from the relevant ethics committee in each country involved in the study. 
Provenance and peer review Not commissioned; externally peer reviewed.

(c) Article author(s) (or their employer(s) unless otherwise stated in the text of the article) 2018. All rights reserved. No commercial use is permitted unless otherwise expressly granted.

\section{REFERENCES}

1 Brand PL, Baraldi E, Bisgaard H, et al. Definition, assessment and treatment of wheezing disorders in preschool children: an evidence-based approach. Eur Respir $J$ 2008:32:1096-110.

2 Martinez FD, Wright AL, Taussig LM, et al. Asthma and Wheezing in the First Six Years of Life. N Engl J Med Overseas Ed 1995;332:133-8.

3 Ducharme FM, Tse SM, Chauhan B. Diagnosis, management, and prognosis of preschool wheeze. Lancet 2014;383:1593-604.

4 Asher MI, Weiland SK. The International Study of Asthma and Allergies in Childhood (ISAAC). Clin Exp Allergy 1998;28:52-66.

5 Janson C, Anto J, Burney P, et al. The European Community Respiratory Health Survey: what are the main results so far? Eur Respir J 2001;18:598-611.

6 Uphoff EP, Bird PK, Antó JM, et al. Variations in the prevalence of childhood asthma and wheeze in MeDALL cohorts in Europe. ERJ Open Res 2017;3:00150-2016-2016.

7 Arshad SH, Stevens M, Hide DW. The effect of genetic and environmental factors on the prevalence of allergic disorders at the age of two years. Clin Exp Allergy 1993;23:504-11.

8 Rancière F, Nikasinovic L, Bousquet J, et al. Onset and persistence of respiratory/ allergic symptoms in preschoolers: new insights from the PARIS birth cohort. Allergy 2013;332:n/a-67.

9 Lodge CJ, Tan DJ, Lau MX, Mxz L, et al. Breastfeeding and asthma and allergies: a systematic review and meta-analysis. Acta Paediatr 2015;104:38-53.

10 van Odijk J, Kull I, Borres MP, et al. Breastfeeding and allergic disease: a multidisciplinary review of the literature (1966-2001) on the mode of early feeding in infancy and its impact on later atopic manifestations. Allergy 2003;58:833-43.

11 Friedman NJ, Zeiger RS. The role of breast-feeding in the development of allergies and asthma. J Allergy Clin Immunol 2005;115:1238-48.

12 Oddy WH, Holt PG, Sly PD, et al. Association between breast feeding and asthma in 6 year old children: findings of a prospective birth cohort study. BMJ 1999;319:815-9.

13 Kull I, Wickman M, Lilja G, et al. Breast feeding and allergic diseases in infants-a prospective birth cohort study. Arch Dis Child 2002;87:478-81.

14 Zutavern A, von Mutius E, Harris J, et al. The introduction of solids in relation to asthma and eczema. Arch Dis Child 2004;89:303-8.

15 Snijders BE, Thijs $C$, van Ree $R$, et al. Age at first introduction of cow milk products and other food products in relation to infant atopic manifestations in the first 2 years of life: the KOALA Birth Cohort Study. Pediatrics 2008;122:e115-22.

16 Wang J, Liu AH. Food allergies and asthma. Curr Opin Allergy Clin Immunol 2011;11:249-54.

17 Keil T, McBride D, Grimshaw K, et al. The multinational birth cohort of EuroPrevall: background, aims and methods. Allergy 2010:65:482-90.

18 McBride D, Keil T, Grabenhenrich L, et al. The EuroPrevall birth cohort study on food allergy: baseline characteristics of 12,000 newborns and their families from nine European countries. Pediatr Allergy Immunol 2012;23:230-9.

19 Duijts L, Jaddoe VWV, van der Valk RJP, et al. Fetal exposure to maternal and paternal smoking and the risks of wheezing in preschool children: the Generation R Study. Chest 2012:141:876-85.
20 Pearce N, Sunyer J, Cheng S, et al. Comparison of asthma prevalence in the ISAAC and the ECRHS. Eur Respir J 2000;16:420-6.

21 Burney $\mathrm{P}$, Chinn S, Jarvis $\mathrm{D}$, et al. Variations in the prevalence of respiratory symptoms, self-reported asthma attacks, and use of asthma medication in the European Community Respiratory Health Survey (ECRHS). Eur Respir J 1996;9:687-95.

22 The International Study of Asthma and Allergies in Childhood (ISAAC) Steering Committee. Worldwide variations in the prevalence of asthma symptoms: the International Study of Asthma and Allergies in Childhood (ISAAC). Eur Resp J 1998:12:315-35.

23 Dharmage SC, Lowe AJ, Matheson MC, et al. Atopic dermatitis and the atopic march revisited. Allergy 2014;69:17-27.

24 Allen KJ, Dharmage SC. The role of food allergy in the atopic march. Clin Exp Allergy 2010:40:1439-41.

25 Malmberg LP, Saarinen KM, Pelkonen AS, et al. Cow's milk allergy as a predictor of bronchial hyperresponsiveness and airway inflammation at school age. Clin Exp Allergy 2010;40:1491-7.

26 Kurukulaaratchy RJ, Fenn MH, Waterhouse LM, et al. Characterization of wheezing phenotypes in the first 10 years of life. Clin Exp Allergy 2003;33:573-8.

27 McGowan EC, Bloomberg GR, Gergen PJ, et al. Influence of early-life exposures on food sensitization and food allergy in an inner-city birth cohort. J Allergy Clin Immunol 2015:135:171-8

28 Caudri D, Wijga A, Scholtens S, et al. Early daycare is associated with an increase in airway symptoms in early childhood but is no protection against asthma or atopy at 8 years. Am J Respir Crit Care Med 2009;180:491-8.

29 Ball TM, Castro-Rodriguez JA, Griffith KA, et al. Siblings, day-care attendance, and the risk of asthma and wheezing during childhood. N Engl J Med 2000;343:538-43.

30 Cheng G, Smith AM, Levin L, et al. Duration of day care attendance during infancy predicts asthma at the age of seven: the Cincinnati Childhood Allergy and Air Pollution Study. Clin Exp Allergy 2014;44:1274-81.

31 Nicolaou NC, Simpson A, Lowe LA, et al. Day-care attendance, position in sibship, and early childhood wheezing: a population-based birth cohort study. J Allergy Clin Immunol 2008;122:500-6.

32 Henderson AJ, Sherriff A, Northstone K, et al. Pre- and postnatal parental smoking and wheeze in infancy: cross cultural differences. Eur Respir J 2001;18:323-9.

33 Lux AL, Henderson AJ, Pocock SJ, et al. Wheeze associated with prenatal tobacco smoke exposure: a prospective, longitudinal study. ALSPAC Study Team. Arch Dis Child 2000;83:307-12.

34 Håberg SE, Stigum H, Nystad W, et al. Effects of pre- and postnatal exposure to parental smoking on early childhood respiratory health. Am J Epidemiol 2007;166:679-86.

35 Magnusson LL, Olesen AB, Wennborg $\mathrm{H}$, et al. Wheezing, asthma, hayfever, and atopic eczema in childhood following exposure to tobacco smoke in fetal life. Clin Exp Allergy 2005:35:1550-6.

36 Grimshaw KE, Maskell J, Oliver EM, et al. Introduction of complementary foods and the relationship to food allergy. Pediatrics 2013;132:e1529-38.

37 Schoemaker AA, Sprikkelman AB, Grimshaw KE, et al. Incidence and natural history of challenge-proven cow's milk allergy in European children-EuroPrevall birth cohort. Allergy 2015;70:963-72.

38 Michel G, Silverman M, Strippoli MP, et al. Parental understanding of wheeze and its impact on asthma prevalence estimates. Eur Respir J 2006:28:1124-30.

39 Asher MI, Keil U, Anderson HR, et al. International Study of Asthma and Allergies in Childhood (ISAAC): rationale and methods. Eur Respir J 1995:8:483-91. 